\title{
Inclusion Exclusion Criterion Sequence Number
}

National Cancer Institute

\section{Source}

National Cancer Institute. Inclusion Exclusion Criterion Sequence Number. NCI

Thesaurus. Code C83299.

An identifier that describes the relative position of inclusion and exclusion criteria data within a series. 